\title{
Electronic cigarettes
}

John Britton

If there is such a thing as a clinician who has not encountered patients whose lives have been blighted or ended prematurely by addiction to tobacco smoking, he or she is unlikely to be a respiratory physician. Respiratory medicine is dominated by the health consequences of smoking, and the poverty that smoking exacerbates. Preventing smoking is fundamental to improving respiratory health. That is why all in respiratory medicine should welcome the advent of electronic cigarettes.

The principal addictive component of tobacco smoke is nicotine. The mechanisms of nicotine addiction are highly complex but include at least two important reward pathways: one mediated directly and immediately by stimulation of dopamine release in the shell of the nucleus accumbens, and one indirectly and after more sustained use through release of dopamine in the nucleus accumbens core in response to stimuli associated with nicotine administration. ${ }^{1}$ In animal models the latter might be a visual stimulus, such as a light that shines when nicotine is administered; in humans, they are likely to include the rasping sensation of smoke in the throat, the smell of tobacco, or possibly also other behaviours associated with drug delivery such as unwrapping and sharing cigarettes. With the establishment of tolerance of dopamine release, however, abstinence from smoking induces intense withdrawal symptoms and cravings to smoke that can be reduced by administering medicinal nicotine, and to a degree by other smoking stimuli. Conventional nicotine replacement therapy products typically provide the first but not the second. Electronic cigarettes, and other devices in development with the potential to provide nicotine by inhalation in a formulation that mimics smoking, do both.

Nicotine is not a carcinogen and has a range of cardiovascular and other effects on the human body ${ }^{2}$ similar in hazard to those of caffeine. Therefore, while many in medicine will argue, sometimes over coffee, that any addiction is unhealthy, immoral and should not be condoned by clinicians, addiction to nicotine is not a

Correspondence to Professor John Britton, UK Centre for Tobacco and Alcohol Studies, University of Nottingham, Clinical Sciences Building, City Hospital, Nottingham NG5 1PB, UK; j.britton@virgin.net major health hazard. Nicotine does not, to practical purposes, kill smokers: smokers are killed by the many other toxins in tobacco smoke. ${ }^{3}$ Therefore, while complete abstinence from all nicotine may be a health or moral ideal, encouraging smokers to substitute tobacco smoke with an alternative, less hazardous nicotine source ('harm reduction') is a far more pragmatic and almost equally effective alternative. ${ }^{1}$ Doing so for all smokers at population level by making effective harm reduction alternatives available as more affordable choices at the point of sale provides an opportunity to achieve population reach that medical smoking cessation services will always struggle to match. The availability of electronic cigarettes and other novel nicotine-containing devices as retail competitors to cigarettes, rather than medicines, thus provides another option for the minority of smokers who use medical services to support quit attempts; and also makes harm reduction a realistic and available alternative for the majority who do not. For this reason, the impact of electronic cigarettes and other devices in development on public health could be massive. That smokers want and will choose lower-hazard alternatives to smoked tobacco, if these are easily available and culturally acceptable, is evident from the widespread substitution of smokeless for smoked tobacco in Sweden, both by existing and new tobacco users. ${ }^{14}$ It is also evident in the rapid rise in use of electronic cigarettes by smokers in the $\mathrm{UK}^{5}$

Electronic cigarettes originated in China, where most of the many products available on the UK market are manufactured. The products currently occupy a regulatory loophole that allows nicotine to be sold without a medicines license, so long as no health claims are made. Consequently there is no obligation for manufacturers or sellers of electronic cigarettes to publish or submit evidence that the products contain nicotine, deliver nicotine, do so reliably, are free from unnecessary or avoidable contaminants or toxins, formulated to protect against accidental overdose or are childproof. Although not to date a problem, there is also no process to prevent promotion of the products to children or others who do not smoke or habitually use nicotine. The limited available evidence suggests that electronic cigarettes vary substantially in their ability to deliver nicotine in the vapour they produce, ${ }^{6}$ and that some deliver very little nicotine at all, though experienced users appear to be able to improve delivery by using two or three rapidly sequential rather than one single puff from the device. ${ }^{7}$ Where analyses of the nicotine solutions used in electronic cigarettes have been carried out these have revealed a range of other constituents including formaldehyde, acetaldehyde, and derivatives of benzene and benzodiazepine, ${ }^{8}$ raising the question of whether these solutions are suitably pure. Most electronic cigarettes deliver nicotine in conjunction with propylene glycol to enable vapour generation, and the longterm effects on the lung of inhalation of this compound are not known. The vapour produced by electronic cigarettes also contains a range of toxins, including some nitrosamines, though at much lower levels than in tobacco smoke. ${ }^{9} 10$ Thus, while there can be no doubt that electronic cigarettes are much less hazardous than tobacco cigarettes, it is far from clear that they are as effective, safe or reliable as might reasonably be expected.

In response to these and other concerns, the UK Medicines and Healthcare Products Regulatory Agency (MHRA) has recently announced proposals to regulate all nicotine containing devices as drugs. ${ }^{11}$ However, in recognition that immediate or overzealous regulation would in effect remove a valuable alternative to smoking from the market and drive many existing electronic cigarette users back to smoking tobacco, the regulation assumes that products that deliver nicotine are effective smoking substitutes, making randomised trial evidence of efficacy unnecessary. Regulation has also been deferred until 2016, providing ample time for producers and sellers to comply. Although there is an argument that regulation imposes costs that might discourage innovation and reduce the affordability of products, the market for these products, and hence the potential for profit, is very large; recouping costs and turning a profit on products that work should not be difficult. Licensed nicotine products are also eligible for 5\% rather than $20 \%$ value added tax in the UK, and will further benefit by being available on prescription, and hence with tacit endorsement from the NHS and health professionals. Responsible manufacturers are therefore likely to comply with regulation relatively easily, and benefit financially from doing so; irresponsible ones will in due course be excluded from the market. 
Some argue that even this permissive regulation is too much, and others that it is not sufficiently robust, but this is not the only controversy associated with electronic cigarettes. Many health professionals are concerned that electronic cigarette use may undo some of the 'denormalisation' of smoking achieved by smoke-free legislation and other measures, and create new smoking role models for children. Some are concerned over how the challenges these products present to current norms of clinical practice will be managed: for example, whether people should be allowed to use electronic cigarettes as inpatients on hospital wards, or in hospital grounds. Many are also discomforted by the fact that the major tobacco companies responsible for the global smoking epidemic are all developing or acquiring electronic cigarettes and/or other nicotine devices, and suspect dark motives behind this move, including perpetuating tobacco smoking, and undermining the international treaty preventing the tobacco industry engaging in tobacco policy. ${ }^{12}$ However, one thing beyond doubt is that tobacco companies are very good at marketing to millions of smokers; they also have the nicotine supply, retail distribution channels and a range of commercial motives to make these products succeed. One of the first new nicotine containing devices to be licensed by the MHRA is likely to be one produced by Nicoventures, a wholly-owned subsidiary of British American Tobacco. So, while pharmaceutical companies or independent producers might be preferred partners for health professionals and policymakers trying to help smokers to quit smoking, the reality is that tobacco companies are likely to become active players in this market. We are entering interesting times.

What matters far more than the ethics of the companies that make these products however is that smokers currently destined for a life of tobacco addiction are offered as many effective escape routes as possible. Electronic cigarettes, and similar products, are clearly one such route. They could also play a massive role in supporting National Health Service (NHS) policies and guidance, enhancing the choice of products available for cessation and harm reduction approaches, ${ }^{13} 14$ and supporting draft proposals to revitalise the concept of a smoke-free NHS, ${ }^{15}$ particularly in mental health, where smoking remains a cultural norm for a population in whom the prevalence of smoking has barely changed in 20 years. ${ }^{16}$ In short, these products represent a huge opportunity to improve the health prospects of millions of smokers in the UK and worldwide. They will present challenges and problems, but are an opportunity not to be missed.

\section{Competing interests None.}

Provenance and peer review Commissioned; internally peer reviewed.

To cite Britton J. Thorax 2013;68:904-905.

Published Online First 12 August 2013

Thorax 2013;68:904-905.

doi:10.1136/thoraxjnl-2013-203973

\section{REFERENCES}

1 Tobacco Advisory Group of the Royal College of Physicians. Harm reduction in nicotine addiction. London: Royal College of Physicians, 2007. http:// www.rcplondon.ac.uk/sites/default/files/documents/ harm-reduction-nicotine-addiction.pdf

2 National Institute for Health and Care Excellence. Tobacco-harm reduction approaches to smoking: Evidence reviews. NICE. 2013. http://www.nice.org. uk/nicemedia/live/14178/64034/64034.pdf (accessed 12 Jun 2013).

3 Russell MA. Low-tar medium-nicotine cigarettes: a new approach to safer smoking. $\mathrm{Br}$ Med J 1976;1:1430-3.

4 Scientific Committee on Emerging and Newly Identified Health Risks. Health effects of smokeless tobacco products. European Commission, 2008.

5 West R, Brown J. Monthly tracking of key perfomance indicators (13). Smoking Toolkit Study.
2013. http://www.smokinginengland.info/ (accessed 13 Jul 2013).

6 Goniewicz ML, Kuma T, Gawron M, et al. Nicotine levels in electronic cigarettes. Nicotine Tob Res 2013;15:158-66.

7 Vansickel AR, Eissenberg T. Electronic cigarettes: effective nicotine delivery after acute administration. Nicotine Tob Res 2013;15:267-70.

8 Commission on Human Medicines Working Group on Nicotine Containing Products (NCPS). Assessment of the constituents of four e-cigarette products. MHRA. 2013. http://www.mhra.gov.uk/home/groups/ comms-ic/documents/websiteresources/con286843. pdf (accessed 12 Jun 2013).

9 Williams M, Villarreal A, Bozhilov K, et al. Metal and silicate particles including nanoparticles are present in electronic cigarette cartomizer fluid and aerosol. PLOS ONE 2013;8:e57987.

10 Goniewicz ML, Knysak J, Gawron M, et al. Levels of selected carcinogens and toxicants in vapour from electronic cigarettes. Tob Control Published Online First: 6 March 2013. doi:10.1136/tobaccocontrol2012-050859.

11 Medicines and Healthcare products Regulatory Agency. The Regulation of Nicotine Containing Products (NCPs). MHRA. 2013. http://www.mhra gov.uk/home/groups/comms-ic/documents/ websiteresources/con286834.pdf (accessed 12 Jun 2013).

12 World Health Organisation. Guidelines for implementation of Article 5.3 of the WHO Framework Convention on Tobacco Control on the protection of public health policies with respect to tobacco control from commercial and other vested interests of the tobacco industry. World Health Organisation Framework COnvention on Tobacco Control. 2008. http://www.who.int/fctc/guidelines/ article_5_3.pdf (accessed 18 Feb 2013).

13 National Institute for Health and Care Excellence. Tobacco-harm reduction. NICE. 2013. http://www. nice.org.uk/nicemedia/live/14178/63996/63996.pdf (accessed 12 June 2013).

14 National Institute for Health and Clinical Excellence. Smoking cessation services in primary care, pharmacies, local authorities and workplaces, particularly for manual working groups, pregnant women and hard to reach communities. NICE Public Health Guidance 10. London: National Institute for Health and Clinical Excellence, 2008.

15 National Institute for Clinical Excellence. Smoking cessation in secondary care: acute, maternity and mental health services. NICE. 2013. http://www.nice. org.uk/nicemedia/live/13017/63459/63459.pdf (accessed 23 Apr 2013).

16 Royal College of Physicians, Royal College of Psychiatrists. Smoking and mental health. London: RCP, 2013. 